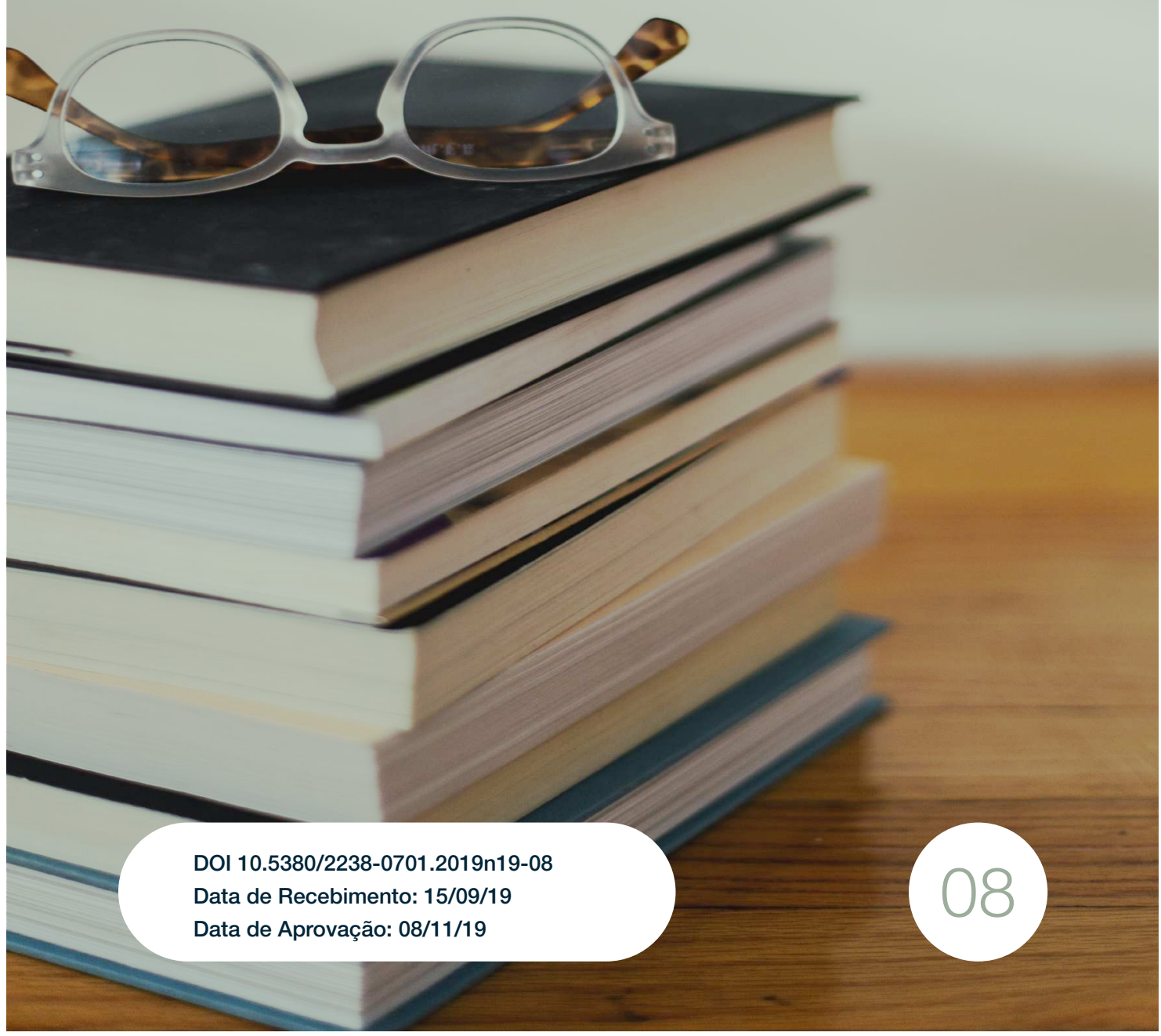


Mitología en la literatura mexicana. Prospecciones teórico-metodológicas 


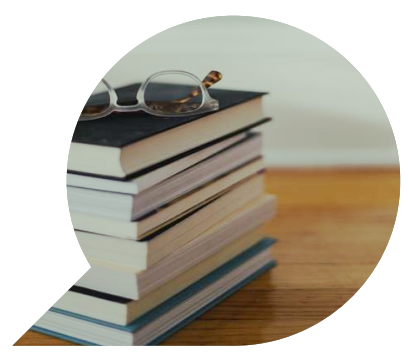

\title{
Mitología en la literatura mexicana. Prospecciones teórico-metodológicas
}

\author{
A mitologia na literatura mexicana: prospecções teóri- \\ co-metodológicas \\ Mythology in Mexican literature. Theoretical-method- \\ ological surveys
}

\begin{tabular}{c}
\hline LUIS ALBERTO PÉREZ-AMEZCUA ${ }^{1}$ \\
\hline SILVIA QUEZADA CAMBEROS ${ }^{2}$ \\
\hline
\end{tabular}

Resumen: En este artículo se demuestra la necesidad de ampliar los estudios mitocríticos en general, a través del ejemplo de la literatura mexicana en particular, en virtud de que se trata de una metodología que ha sido poco utilizada por los investigadores. A pesar de ser epistemológicamente sólida y capaz de generar análisis sobre identidad cultural y otras cuestiones de interés, las posibilidades de realización de estudios desde este horizonte crítico no han sido suficientemente discutidas. Luego de mostrar de manera somera algunos fundamentos de la mitocrítica y de ofrecer un corpus no exhaustivo de textos literarios mexicanos susceptibles de ser

1 Doctor en Humanidades por la Universidad Autónoma Metropolitana. Maestro en Estudios de Literatura Mexicana por la Universidad de Guadalajara (México). Profesor investigador en el Departamento de Artes y Humanidades del Centro Universitario del Sur de la Universidad de Guadalajara. E-mail: perez.amezcua@academicos. udg.mx.

2 Doctora en Humanidades y Artes por la Universidad Autónoma de Zacatecas. Profesora investigadora en el Departamento de Letras del Centro Universitario de Ciencias Sociales y Humanidades de la Universidad de Guadalajara. E-mail: silvia.quezada09@gmail.com. 
abordados desde esta perspectiva, se concluye que es deseable emprender investigaciones de esta naturaleza que: 1) incluyan una perspectiva interdisciplinaria mediante la consideración del componente fisiológico de la imaginación, y 2) contemplen la importancia de la "traducción" del mito para considerar la condición global de la cultura y de este modo contribuir a generar un diálogo a propósito de los retos del mundo contemporáneo.

Palabras clave: Mitocrítica; Literatura mexicana; Teoría literaria; Estudios literarios; Mitos mesoamericanos.

Resumo: Este artigo põe em evidência a necessidade de se ampliar os estudos mitocríticos em geral, por meio do exemplo da literatura mexicana em particular, em virtude de tratar-se de uma metodologia ainda pouco utilizada pelos pesquisadores. Apesar de constituírem uma perspectiva sólida e capaz de gerar análises sobre identidade cultural e outras questões de interesse, estudos realizados a partir desse horizonte crítico ainda não foram suficientemente discutidos. Depois de mostrar de maneira sumária alguns dos fundamentos da mitocrítica e de oferecer um corpus não exaustivo de textos literários mexicanos passíveis de serem abordados desta maneira, nossa conclusão é que seria desejável empreender investigações dessa natureza que: 1) incluam uma perspectiva multidisciplinar por meio da consideração do componente fisiológico da imaginação e; 2) contemplem a importância da "tradução" do mito para se considerar a condição global da cultura e, desta maneira, gerar um diálogo intercultural a respeito dos desafios do mundo contemporâneo.

Palavras-chave: Mitocrítica; Literatura mexicana; Teoria Literária; Estudos literários; Mitos mesoamericanos.

Abstract: In this article the need of widening the mythcritic studies in general, through the example of Mexican literature in particular, is demonstrated, since it is a methodology that has not been used sufficiently by researchers. Even though it is epistemologically solid and able to generate analyses on cultural identity and other subjects of current interest, the possibilities of realization of studies 
from the critical horizon has not been discussed sufficiently. After showing briefly some fundaments of mythcriticism and offering a non-exhaustive corpus of Mexican literary texts susceptible of being addressed from this perspective, it is concluded that it is desirable to undertake research of this nature which: 1) include an interdisciplinary perspective through the consideration of the physiological component of the imagination, and 2) contemplate the importance of myth "translation" to consider the global condition of culture and therefore contribute to generate an intercultural dialogue regarding contemporary world's challenges.

Keywords: Mythcriticism; Mexican literature; literary theory; literary studies; Mesoamerican myths.

\section{Introducción}

Raíz sois, joh hermanos!, de la voz que florece en mí, de las palabras donde pesa lo inefable del balbuceo de la tierra, el conjuro de los cielos y el canto del espíritu

(Agustí Bartra, Quetzalcoatl, 6, vv. 6-8)

En la década de 1980, Hans-Georg Gadamer reavivó y difundió insistentemente sus inquietudes respecto del mito en la cultura contemporánea, presentes ya en "Mito y razón", un texto de 1954. Sus reflexiones sobre las relaciones entre el mito y la ciencia o el mito y la religión - esto es, sobre aspectos de la conducta y la industria de miles de millones de personas - pusieron en evidencia la necesidad de considerar a estos relatos como un elemento fundamental en la construcción del imaginario de grandes colectivos. De hecho, para el alemán, las razones del mito son intrínsecas al ser humano en tanto que su fenomenología las considera parte esencial del lenguaje, esto es, tanto de los modos de producción de imágenes como de conceptos. Las formas narrativas míticas, como las llama Gadamer, son poseedoras de una lógica y una verdad peculiares, y, por tanto, exigen un modo de estudio igualmente peculiar. El ser humano es, como ha demostrado la antropología cultural, un ser básicamente ritual. La repetición y la costumbre, la continuidad 
que implica el ritual, son necesarias para la vida social, tanto desde el punto de vista sagrado como desde el profano. Y si es cierto que la literatura es siempre el resultado y el producto de un ambiente sociohistórico determinado - y esta es la premisa-, entonces es también cierto que las cuestiones del mito y del rito que lo vehiculan no pueden ser ignoradas por los estudios literarios.

Desde que el hombre comenzó a practicar el arte literario se dio cuenta de que las palabras, al agruparse de ciertas maneras, podían expandir sus poderes de representación y de congregación, por lo que comenzó a utilizarlas para explicarse el mundo a partir de los relatos que iban formando y a compartir con su comunidad dicha explicación. Estos relatos son los mitos, un discurso de base simbólica que respondía sus preguntas y dotaban al universo del ser humano y al ser humano mismo de un sentido. Es relativamente sencillo comprobar que los mitos -y sus símbolos - están presentes en la literatura de manera profusa y frecuente. En algunos casos los mitos se encuentran en la gramática textual de una forma casi obsesiva. La identificación se realiza inmediatamente. En otros escritores y en otros textos, en cambio, los mitos se encuentran de forma latente. Es necesario descifrar el código que actúa en la creación literaria y que reformula el mito mediante distintos artificios. A veces incluso los mitos explícitos, puestos ahí de manera consciente, pueden no estar en concordancia con la estructura imaginaria que realmente los puso ahí, y por eso es necesario, una vez más, descifrar el código. Y uno de los instrumentos para descifrarlo es la mitocrítica.

Ahora bien, la literatura mexicana contemporánea es heredera de una larga tradición, que es sometida a cuestionamientos que generan los estilos propios de los autores que, sin embargo, son en conjunto una unidad compleja, sintetizadora de momentos y modos míticos diversos que pueden revelar una historia cultural paralela. La literatura mexicana ha sido una de las más importantes de Hispanoamérica desde su nacimiento. Nuestro momento histórico despierta el interés respecto a las formas que adoptará la literatura en los próximos años: cuáles serán sus orientaciones imaginarias y míticas, qué será lo que la guíe y la produzca. Heredera de la cultura prehispánica y de la occidental, y resultado del mestizaje de la Conquista, no sorprende que la literatura mexicana abunde en referencias y alusiones mitológicas provenientes de sus orígenes grecolatinos, indígenas, indoeuropeos, judeocristianos y 
otros más derivados del desarrollo histórico del país, de su sincretismo y su riqueza culturales.

Al repasar la historia de la literatura mexicana encontramos infinidad de textos con títulos o temas relacionados con la mitología, ante lo que cabe preguntarse cuál es la razón de esta abundante utilización de los mitos, cuáles son los modos en que han sido y están siendo reescritos y qué significado - qué sentido hermenéutico - tienen estas reescrituras. Nuestro objetivo no es desde luego responder a todas estas preguntas en este trabajo (jsería imposible!) sino plantear que es posible hacerlo a través de un mitoanálisis (el término es clave) que dé cuenta de las connotaciones culturales y políticas en un contexto local que se inserta naturalmente en uno mayor, global. En este caso, nos apoyaremos en el análisis del mito azteca de Quetzalcóatl en dos textos literarios y en dos prácticas culturales para demostrar cómo el estudio del mito trasciende el ámbito de lo literario y ofrece otras opciones para la generación y aplicación de conocimiento.

\section{Fundamentos de la mitocrítica}

Busquemos los ritos. Busquemos cómplices. (Jaime García Terrés, "Teonanácatl”)

La mitocrítica es un sistema de interpretación antropológica de la cultura ideado por el filósofo francés Gilbert Durand (1921-2012). Sus bases epistemológicas y teóricas se exponen en Las estructuras antropológicas del imaginario. Introducción a la arquetipología general (1960), donde se reúnen estudios sobre mitos y símbolos en diferentes culturas realizados por antropólogos, etnólogos e historiadores de la religión, así como otras aportaciones de investigaciones en áreas como psicología, psicoanálisis, lingüística, sociología y reflexología, para proponer un acercamiento al sentido simbólico a partir de una comprensión del funcionamiento de las estructuras de lo imaginario. Es necesario resaltar la importancia capital que tiene el hecho de que se contemple una base reflexológica, es decir fisiológica, en estos intentos de definir la manera en la que se construye el imaginario del homo sapiens. Volveremos a ello en las conclusiones. Es de destacar la naturaleza eminentemente interdisciplinaria de la mitocrítica, en la que insisten más tarde la mayoría de 
los investigadores, en especial Losada Goya (2015, p. 15; 2016, p. 11).

Durand se desvincula del estructuralismo de Claude Lévi-Strauss, aunque reconoce el valor de sus propuestas y lo brillante de sus trabajos. De hecho, un concepto clave para la mitocrítica, el de mitema, es tomado del etnólogo francés. Durand acepta que para comprender el mito es preciso reconstruir su estructura, pero para él no se trata de estructura, en singular, sino de estructuras, en plural, estructuras que son, además, dinámicas. De esta forma su análisis se diferencia fundamentalmente en la creación de un tercer nivel de lectura más allá de lo sincrónico y de lo diacrónico: el nivel arquetípico, que además de considerar las redundancias o repeticiones temáticas reagrupa los símbolos en constelaciones por sus convergencias y revela la operatividad del mito o los mitos en el trasfondo de la configuración del relato. Esta obra y sus planteamientos serán completados con La imaginación simbólica (1964).

En De la mitocrítica al mitoanálisis. Figuras míticas y aspectos de la obra (1979), Durand presenta ya una formulación metodológica de análisis de la obra de arte denominada ya propiamente mitocrítica. La palabra fue forjada siguiendo el modelo del término psicocrítica utilizado en 1949 por Charles Mauron (1899-1966), quien así se refería a un método de crítica literaria de base psicoanalítica que centra el proceso hermenéutico en el estudio de las psicopatologías o "complejos" de los autores que se manifiestan a partir de las repeticiones (obsesiones) textuales-autorales, aspecto que para Durand no es determinante o suficiente, aunque sí útil. ${ }^{3}$ La mitocrítica adopta como postulado de base que una "imagen obsesiva", un símbolo medio, para quedar integrado en una obra (y además para ser integrante, motor de integración y de organización del conjunto de la obra de un autor) debe "anclarse en un fondo antropológico más profundo que la aventura personal registrada en los estratos del inconsciente biográfico" (DURAND, 2003, p. 188). Aunadas a las psicobiográficas, deben integrarse las consideraciones socioeconómicas, es decir, el contexto, así como las relaciones entre el texto y sus estructuras formales. Así, Durand considera las obras de arte no sólo como visiones del mundo sino como universos propios que ordenan y articulan valores que, por su procedencia, exigen para su comprensión una referencia

3 Mauron fue un crítico reconocido por su libro Des métaphores obsédantes au mythe personnel (1963). Entre sus obras se encuentran Mallarmé l'obscur (1941); Introduction à la psychanalyse de Mallarmé (1950); Note sur la estructure inconsciente de Van Gogh (1953); L'inconscient dans l'oeuvre et la vie de Racine (1954); Psychocritique du genre comique (1964), etcétera. Otros críticos que siguieron esta línea son Marie Bonaparte que estudió a Edgar Allan Poe, y René Laforgue que analizó a Charles Baudelaire. 
última al mito. En sus siguientes obras el método se va perfeccionando, valiéndose de todos los recursos que revelen al mito y permitan su aprehensión y comprensión. ${ }^{4}$

Se propone, pues, un acercamiento al sentido a partir de una comprensión de la dinámica de estas estructuras de lo imaginario que exponen los mitos y sus símbolos, reunidos en un decorado único, peculiar, pero que siempre alude a las lecciones profundas del mito. Sobre el carácter dinámico de las estructuras míticas, Losada Goya recuerda que "Como el mito, la mitocrítica también es dinámica" (2016, p. 11).

Un concepto que parece haber olvidado la mitocrítica actual es el de mitoanálisis, aunque intente realizarlo de una manera que no lo nombra. Durand afirma que "la mitocrítica es una prolongación de las 'nuevas críticas' literarias y artísticas de estos últimos años, mientras que el mitoanálisis deja entrever una perspectiva más ambiciosa que quisiera descifrar amplias orientaciones míticas de momentos históricos y culturales colectivos" (2013, p. 14). Debe destacarse este intento de desciframiento y la idea socioespacial, topológica, de esta consideración teórica, pues debe importar a los estudios mitocríticos de la literatura mexicana. El término está forjado sobre el modelo del psicoanálisis, y define un método de estudio científico de los mitos con el fin de extraer de ellos no sólo el sentido psicológico sino también el sociológico. Este mitoanálisis "amplía el campo individual del psicoanálisis, siguiendo la trayectoria de la obra de Jung, y que, superando la reducción simbólica simplificadora de Freud, se basa en la afirmación del 'politeísmo' de las pulsiones de la psique” (DURAND, 2013, p. 350). James Hillman (19262011) muestra, según Durand, lo que aporta al análisis de tipo junguiano: "Mientras que el célebre psiquiatra de Zúrich generaliza y uniformiza por ejemplo el arquetipo de Anima, el mitoanálisis discierne distintos tipos de ánima según las tipologías de la mitología antigua: Venus, Deméter, Juno, Diana, etc." (2013, 350). Este mitoanálisis "psicológico" se asocia así con una acepción sociológica, ya que los personajes mitológicos pueden ser objetos de un análisis sociohistórico y los dioses y héroes aparecen y desaparecen según un ritmo que marca los momentos de la historia sociocultural. Anotemos aquí una tipología para apoyar nuestro ejemplo: Quetzalcoatl.

El mitoanálisis "intenta entrever, detrás de los ejemplos concretos

4 Cf. Ciencia del hombre y tradición. El nuevo espíritu antropológico (1999); Mitos y sociedades. Introducción a la mitodología ( 2003); Beaux-arts et archétypes. La religion de l'art (1989), entre otros. 
de la mitocrítica textual, el juego dinámico gracias al cual una agrupación humana vinculada por un destino cultural tramita sus temores y sus deseos, sus puntos de vista y sus visiones del mundo, para constituir el alma por la cual se identifica y sobrevive en cuanto a tal a través de los avatares y de las vicisitudes del devenir" $(2013,14)$. Hay que destacar aquí que esta explicación es fundamental en tanto implica la manera en que se dota de identidad, y en nuestro caso porque servirá de apoyo para reflexionar sobre la identidad mexicana, un asunto que ha estado en la agenda por lo menos desde hace ochenta años. El mitoanálisis intenta delimitar los grandes mitos directores de los momentos históricos y de los tipos de grupos y relaciones sociales: "Se trata de un mitoanálisis porque con frecuencia las instancias míticas están latentes y difusas en una sociedad, e incluso cuando están patentes la elección de uno u otro mito explícito escapa a la conciencia clara, aunque sea colectiva" (DURAND, 2013, p. 350).

La teoría y la crítica del siglo XX fueron fecundas y ofrecieron diversas perspectivas de aproximación al hecho literario. Historia literaria, sociología de la literatura, lingüística, retórica, marxismo, psicoanálisis, estructuralismo, sociocrítica, semiótica, etcétera, han contribuido a formar un corpus que nos permite ahora acercamientos y revisiones mucho más completos de la literatura nacional y establecer comparaciones más ricas. La mitocrítica y el mitoanálisis ofrecen una posibilidad de descubrimiento novedoso y crítica coherente de la literatura y de la forma en la que entra en diálogo con el mundo, con el espíritu del hombre. Nos parece conveniente intentar un acercamiento de esta naturaleza en nuestro continente debido a su perspectiva y alcance humanísticos. Gilbert Durand, asegura Blanca Solares, "defiende desde siempre la urgente necesidad de tender puentes entre las ciencias humanas para desembocar en la ciencia del hombre [...] nunca ha pretendido rechazar los resultados de nadie, sino, por el contrario, ofrecer un terreno de entendimiento común" (2013, p. 8).

Quizá debido a esta necesidad de entendimiento humano, ante las crisis de fin e inicio de siglos, la mitocrítica ha ganado un lugar en los estudios literarios, si bien el camino no ha sido fácil. Las dificultades de ofrecer una definición exhaustiva del mito ${ }^{5}$ de explicar suficientemente

5 No obstante, Losada Goya ofrece una definición que reúne las propuestas anteriormente por varios teóricos y que resulta muy operativa; para él el mito es un "relato explicativo, simbólico y dinámico, de uno o varios acontecimientos extraordinarios personales con referente trascendente, que carece en principio de testimonio histórico, 
el funcionamiento del símbolo constituyen un obstáculo para una aplicación más extensa de la mitocrítica, pero al mismo tiempo puede ser un estímulo tanto teórica como metodológicamente, para integrar una práctica que permita una nueva manera de conocer al ser humano en este complejo inicio del siglo. La pluralidad de acercamientos, representaciones y tratamientos forma parte de la esencia del mito, así como la ambigüedad y casi la contradicción forman parte del símbolo. Lo que se ha logrado con este enfoque es integrar y contrastar diversas aportaciones, observar las modificaciones conceptuales relacionadas con un contexto y una percepción del mundo determinados, así como aproximarse a la literatura occidental y a los lectores de hoy de una manera que resulte útil, que cause un impacto en virtud de las revelaciones íntimas, interiores, que es capaz de ofrecer.

Independientemente de las cuestiones teóricas, vale la pena mencionar que en la práctica la mitocrítica permite estudiar mitos antiguos, medievales y modernos, analizar los mecanismos de construcción mítica del periodo correspondiente y abordar cuestiones relacionadas con su recepción. Los estudios teóricos plantean la cuestión del mito desde perspectivas muy variadas. Existen planteamientos basados en la historia de la literatura; aproximaciones al tematismo estructural; relaciones entre mitología y filosofía, psicoanálisis y antropología; se realizan indagaciones en el significado de los mitos según diversas perspectivas (político, social, antropológico), etcétera.

Los estudios mitocríticos, además, ya no hacen referencia únicamente a la literatura, sino que la relacionan con otras manifestaciones artísticas en las que se reincorporan las figuras y temas míticos, como el cine, la pintura, la fotografía o la ópera. De esa transversalidad entre las distintas artes surge un mejor conocimiento del mito, de nuestra época y de nosotros mismos, que es la función que deben cumplir la mitocrítica de la literatura y el mitoanálisis.

\section{La riqueza mítica de la literatura mexicana}

Comprenderás entonces, María-Marie, que hay dos nuevas Ciudad

se compone de una serie de elementos invariantes reducibles a temas y sometidos a crisis, presenta un carácter conflictivo, emotivo, funcional, ritual y remite siempre a una cosmogonía o a una escatología absolutas, particulares o universales" (Losada Goya 2015, 9). 
de México

que no figuran en los atlas y que, sin embargo, son tan reales como Londres o Eldorado.

(Rodrigo Fresán, Mantra)

Al correlacionar una somera revisión de nuestra historia literaria (contexto), el origen, trama y temas de los textos (hecho literario) y la mitocrítica (teoría literaria), es evidente el potencial que ofrece una aproximación de esta naturaleza, que abre la puerta no sólo a una mitocrítica sino también a mitoanálisis más amplios. Como un ejemplo que muestra la recurrencia a temáticas míticas de diversos escritores mexicanos ofrecemos la enumeración de algunos títulos de textos incluidos en la Antología del poema en prosa en México, de Luis Ignacio Helguera (1993), aunque lo mismo puede hacerse con otras recopilaciones. Nos encontramos con "Sysipho era", de Carlos Díaz Dufoo II;6 "José de Arimatea" y "Eva", de Ramón López Velarde; el excepcional "A Circe", de Julio Torri; "La Venus de Milo", "Don Quijote", "Noé", "Salomé” y "Job”, de Salvador Novo; "El hermano del hijo pródigo" y "Anti-Orfeo", de Owen; "El viaje”, de Álvaro Mutis, "Adán y Eva", de Jaime Sabines; "Teonanácatl", de Jaime García Terrés; "Ángel”, de Tomás Segovia; "Naxos", de Elsa Cross, "Las Meigas" de Jorge Esquinca; "Volver a Ítaca” de Héctor Carreto; "Dos caras tenía Jano" de Jaime Moreno Villarreal, entre otros. Como puede apreciarse, los motivos de la mitología grecolatina y bíblica son más abundantes que los de la mitología mesoamericana, lo que sin duda se debe a los factores coloniales de la configuración del país.

No obstante esta riqueza, hasta ahora los estudios mitocríti-

\footnotetext{
6 A propósito de las figuras de Prometeo, Sísifo y Ulises en la literatura mexicana, son de destacar textos recientes de autores jóvenes, como son "Nuevo Prometeo", de Óscar de Pablo (1979), incluido en Sonata para manos sucias (2005); "Sísifo mira la TV" de Carlos Vicente Castro (1975), publicado en Luvina, 55, verano 2009; y "Ulises (negándose a volver)", de Mijail Lamas (1979) en El canto y la piedra (2017).

7 Teonanácatl es un hongo alucinógeno mexicano que se utilizaba con fines rituales, como atestiguan algunos cronistas. Su representación en algunos códices lo vincula con Quetzalcoatl, y de ahí una de las formas de vincular a la literatura con el mito, esto es, de una manera directa, a través de aludir o incluir a un personaje mítico o bien a través de relaciones derivadas por atributos o relaciones culturales, como en el texto de García Terrés, incluido en Carne de dios (1964). Teonanácat/ significa, precisamente, "la carne de los dioses". El valor trascendental es lo que legitima la aproximación mitocrítica. Otra forma de vinculación, creemos, es la indirecta, la que reescribe a los mitos por temas, como en el caso de las novelas Lampa vida (1980) de Daniel Sada, El gran pretender (1992) de Luis Humberto Crosthwaite o Mantra (2001) de Rodrigo Fresán, y los relatos de La sierra y el viento (1977) de Eduardo Cornejo, Relatos de mar, desierto y muerte (1980) de Ricardo Elizondo, Tijuanenses (1989) de Federico Campbell y Tierra de nadie (1999) de Eduardo Antonio Parra, que reúnen "trazas míticas tanto de cosmovisiones regionales de la sierra y el desierto (seris, tarahumaras, yaquis) como de la mitología nacional azteca (Coatlicue, Quetzalcoatl, mitos cosmogónicos, etiológicos y escatológicos); animismo, tiempo y decires míticos; mitologización arcaísta de espacios urbanos y de elementos de cultura popular" (cf. Inventario de mitos prehispánicos en la literatura latinoamericana, Universitat Autònoma de Barcelona, disponible en <http://grupsderecerca.uab.cat/catalogomitos/>.
} 
cos han sido realizados con un corpus primordialmente europeo. Hasta donde sabemos, son pocos los investigadores que han estudiado a autores latinoamericanos como Cortázar, Borges y García Márquez. ${ }^{8}$ Menos aún son quienes lo han hecho con escritores mexicanos, aunque ya se han dado los primeros acercamientos con trabajos como los de Ruiz Otero, quien estudia los mitos en Rulfo, relacionando erotismo y religiosidad. ${ }^{9}$ Es muy estimulante también corroborar la existencia de algunos artículos como el de González Treviño sobre una obra de Luisa Josefina Hernández o el de García Peña sobre una novela de Aline Petersson. ${ }^{10}$

En México David García Pérez publicó hace más de una década un libro que desde la perspectiva mitocrítica estudia el tema de la muerte en Juan Rulfo, por lo que se trata de un trabajo pionero, aunque no reconoce su deuda con la obra de Durand, a quien apenas menciona en una nota al pie. ${ }^{11}$ A propósito de Rulfo, el catalán Eduardo Subirats le dedica un capítulo a la novela Pedro Páramo del escritor mexicano, tratando temas como el descensus ad inferos, Edipo y las diosas de México, en especial la Diosa Luna. ${ }^{12}$

Esperemos que el número de trabajos mitocríticos aumente en los próximos años con la deseable integración de grupos de investigación de jóvenes que conozcan estas posibilidades analíticas. La nómina de escritores mexicanos - y latinoamericanos - que han incluido mitos prehispánicos en sus obras no es corta, por lo que puede afirmarse que hay material más que suficiente para trabajar.

Como un caso ejemplar de las posibilidades no sólo mitocríticas sino mitoanalíticas de la literatura mexicana, se ofrece aquí el de la figura

\footnotetext{
8 Algunos ejemplos del ámbito hispánico son Francisco Javier Capitán Gómez, "Orfeo y Eurídice en un relato de Julio Cortázar"; Cristina Coriasso, "El laberinto como símbolo del referente inexistente: una comparación entre Borges y Buzzati", ambos en Amaltea. Revista de mitocrítica; Erea Fernández Folgueiras y Sara Santos Hurtado, "La reescritura americana de Antígona en el siglo XX. La hojarasca, de Gabriel García Márquez y A Time to Die, de Eric Bentley", en José Manuel Losada Goya (coord.) Mito y mundo contemporáneo. La recepción de los mitos antiguos, medievales y modernos en la literatura contemporánea (Bari: Levante Editori, 2010, pp. 311-330). 9 Silvia Ruiz Otero, "Rulfo y sus mitos: religiosidad y erotismo", en José Manuel Losada Goya (coord.) (2010), Mito y mundo contemporáneo. La recepción de los mitos antiguos, medievales y modernos en la literatura contemporánea.

10 Ana Elena González Treviño, "Convertir el caos en cosmos: la lógica del laberinto en Apocalipsis cum figuris de Luisa Josefina Hernández"; Lilia Leticia García Peña, "Viajes paralelos desde el mito de Aracné: los abismos interiores de Aline Petersson", ambos en Amaltea. Revista de mitocrítica.

11 David García Pérez, Morir en Comala. Mitocrítica de la muerte en la narrativa de Juan Rulfo (México, Ediciones Coyoacán, 2004).

12 Eduardo Subirats, Mito y literatura, México: Siglo XXI, 2014. En este trabajo también se analizan, desde un enfoque que relaciona el mito con la filosofía, las novelas Yo el Supremo del paraguayo Augusto Roa Bastos, Los ríos profundos del peruano José María Arguedas, Macunaíma de Mário de Andrade y Grande Sertão: Veredas de João Guimarães Rosa, ambos brasileños.
} 
de Quetzalcoatl. Elisa Ramírez dice que es "héroe fundador y civilizador, dios, príncipe, artista y artesano, Lucero de la Mañana [...] una de las figuras - o complejo simbólico - más fascinantes del México antiguo" (2002, p. 50). Son muchos los textos que se han basado en este mito fundacional de la cultura mexicana, pero aquí sólo queremos destacar dos. También, queremos hacer mención - para subrayar la idea de complejo simbólico - otras dos manifestaciones culturales recientes. No se hará ninguna crítica formal sino sólo una exposición de notas sobre las posibilidades mitocríticas en un espacio más amplio. Los libros son Quetzalcoatl del catalán Agustí Bartra y la novela homónima del expresidente mexicano José López-Portillo y Pacheco.

En el primer caso se trata de un espléndido poema extenso. "Como poeta, lo que me importaba era crear, de ninguna manera glosar: ser fiel a la prodigiosa figura desde lo hondo, pero comunicándole una nueva actualidad palpitante, aprovechando los sutiles hilos de la trama de oro del mito antiguo para tejer por mi cuenta" (BARTRA, 1960, p. 12). El poema de Bartra reapareció como facsímil en 2008 de la edición original de 1960 con motivo de los 100 años del natalicio del autor, lo que demuestra al mismo tiempo la vigencia del interés y la importancia del texto en la bibliografía de quien fue exiliado en México por treinta años. El poema está compuesto por quince cantos más una sección de notas en las que incluye "tanto para una mayor comprensión del personaje como de mi interpretación en el poema, la transcripción de algunos fragmentos capitales del relato sobre Quetzalcoatl, procedente de códices prehispánicos" (BARTRA, 1960, p. 165). La versión que ofrece Bartra es la de Ángel María Garibay Kintana, esto es, hay una mediación por traducción del náhuatl al español. Luego de estas transcripciones aparecen anotaciones para cada canto, en donde Bartra refiere a Miguel León-Portilla - uno de los investigadores (y traductores) del México antiguo más importantes - y a Laurette Séjourné - antropóloga italiana naturalizada mexicana y, por tanto, también, aunque en otro nivel, traductora - y equipara el descenso a los infiernos del dios mexicano con el de Orfeo, entre otras reflexiones para cada sección.

El segundo texto es una novela compuesta por once capítulos, un prólogo "en el origen" y un epílogo, así como una serie de notas sobre las fuentes de las que el político mexicano se valió para construir su texto. El autor indica las tres versiones que conoce de la figura de Quetzal- 
coatl, la del dios, la de "un personaje misterioso, presente en la tragedia de la Conquista" (LÓPEZ-PORTILLO Y PACHECO, 1965, p. 172) y la de los sacerdotes que recibían su nombre del culto a la deidad. En la obra, dice López-Portillo, se trata de la figura humana, pero "con las implicaciones conceptuales del principio filosófico con el que se identifica dentro de la Teogonía india" (LÓPEZ-PORTILLO Y PACHECO, 1965, p. 172). Se señalan asimismo algunos mecanismos de técnica narrativa, como la empleada en el capítulo de la profecía, para el cual "nos valimos del procedimiento de integración, consistente en unificar en un solo cuerpo de expresión los pasajes proféticos del Chilam Balam de Chumayel [...] algunas expresiones del azoro de Moctezuma, y la relación que hicieron los compañeros de Cuauhtémoc, que cita Sahagún, en la que de manera impresionante consta el relato de lo sucedido" (LÓPEZ-PORTILLO Y PACHECO, 1965, p. 173).

Como puede observarse, resulta curiosa la necesidad de los autores de explicar un tema por el que al parecer se sienten rebasados, como si se tratara de un peso histórico superlativo -y agregaríamos simbólico - que exigiese una reorientación - una canalización semiótica- o incluso casi una disculpa. De la obra de López-Portillo poco se ha dicho críticamente, y lo que puede hallarse tiene connotaciones místicas y gnósticas que no dejan de ser interesantes. Recuérdese que muchos presidentes de México fueron masones, y López-Portillo lo fue. Al final, se trata de dos orientaciones distintas pero convergentes de las motivaciones del re-conocimiento de la historia mexicana gracias a las nuevas políticas educativas postrevolucionarias que ofrecieron, a través de la academia, nuevas luces sobre el pasado de la nación.

Para mostrar la pervivencia del mito de Quetzalcoatl y su manifestación globalizada, queremos hacer mención a que, en 2018, en el Cheonan World Dance Festival de Corea del Sur, un ballet mexicano logró el segundo lugar entre 52 países. La noticia y el video de la pieza central circularon por redes sociales y prensa. Interesa hacer notar la intermedialidad del mito que ha pasado de la tradición oral, a los códices, a las crónicas, a la literatura y a la danza. El número se basa en pasos de danzas concheras y de otras orientaciones que aún se practican de manera ritual y que se mezclan con técnicas de danza contemporánea. La música está basada en instrumentos prehispánicos y los bailarines hacen sonar el ayacaxtli, una sonaja. Los vestuarios son muy coloridos y 
hechos de plumas de aves, a la usanza de los atuendos aztecas.

Figura 1. Quetzalcóatl, presentación del grupo de danza mexicano.

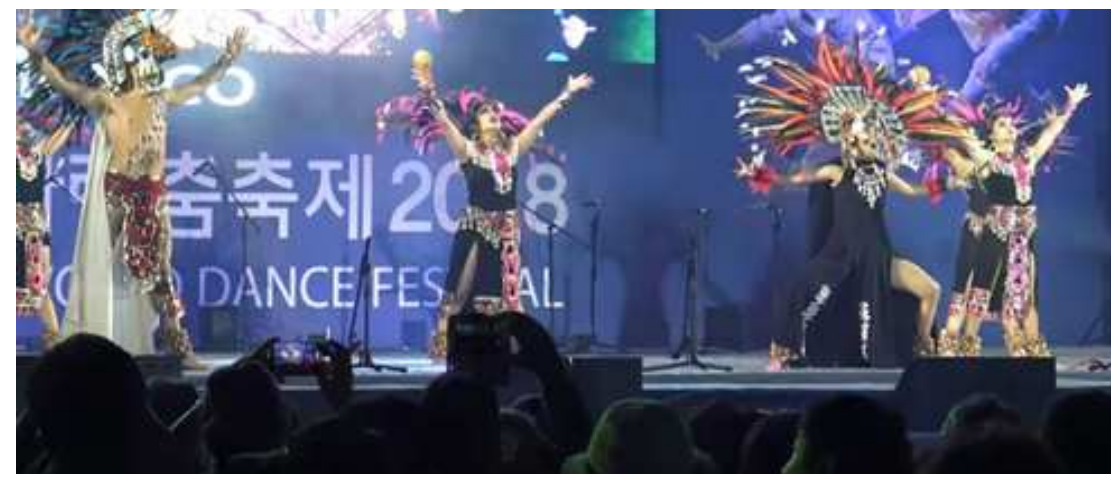

Fuente: Captura de pantalla de elaboración personal desde el canal de YouTube de la agrupación Arte y Folklor. MÉXICO de Aranza Zu López, https://www.youtube.com/watch?v=YFFpa7BFBKo

Otro ejemplo: el 1 de diciembre de 2018, en la toma de posesión del nuevo presidente de México, Andrés Manuel López Obrador, los representantes de los sesenta y ocho pueblos originarios le entregaron un bastón de mando coronado por una cabeza de Quetzalcoatl, en su representación de serpiente emplumada. El bastón "fue hecho a mano por varias comunidades mixes de Oaxaca, más específicamente, del pueblo Ayuukjä'äy [...] es de madera de ahuehuete, árbol con un valor ceremonial muy profundo" (Noticieros Televisa, 2018). Es notable cómo este mito se hace presente en la vida pública de un país y retrotrae simbólicamente la historia sagrada de una cultura originaria, lo que demuestra una vez más la naturaleza ritual del ser humano. ${ }^{13}$

13 Cf. Gadamer, "Acerca de la fenomenología del ritual y el lenguaje", en Mito y razón, Barcelona, Paidós, 1997, en especial p. 91, en donde afirma que "el rito no es una forma de hablar, sino una forma de actuar. Donde se procede ritualmente, el hablar se convierte en una acción [...] La dimensión en que se realiza lo ritual es, sin embargo, siempre un comportamiento colectivo". 
Figura 2. Toma de protesta del presidente de México Andrés Manuel López Obrador. Gobierno de México, Presidencia de la República.

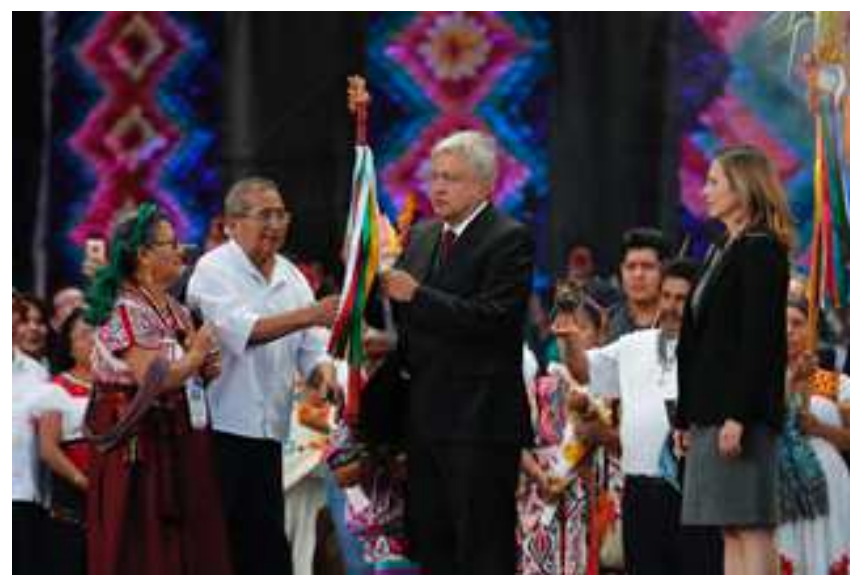

Fuente: https://www.gob.mx/presidencia/galerias/ceremonia-de-entrega-de-baston-de-mando-de-pueblos-originarios-y-mensaje-a-la-nacion

Estas múltiples opciones de estudios de obras literarias en lo individual (lo sincrónico) y de las manifestaciones diferenciadas del mito en otros soportes o continuaciones (lo diacrónico) desde diversas perspectivas deben, no obstante, no perder de vista que han de procurar converger en intentos hermenéuticos de mayores dimensiones (lo arquetípico) expresados en los mitoanálisis a que aspiraba Durand.

\section{Conclusiones}

te propongo que caminemos una vez más por nuestros viejos rumbos y escuchemos los oráculos que murmuran desde las rendijas de las alcantarillas

la cabeza de Orfeo y la lengua emplumada de Quetzalcóatl.

(Fernando del Paso, Palinuro de México)

Ya adelantábamos que las consideraciones teóricas de la mitocrítica incluían la parte fisiológica - biológica - de la manera en la que el ser humano construye su imaginario y por lo tanto sus esquemas mentales (esquemas que determinan orientaciones psicológicas y por tanto emociones y conductas). Aunque la propuesta de Durand es interdisciplinaria, la mitocrítica que le siguió ha olvidado casi por completo salvo dos 
excepciones, ambas en El retorno de Hermes. Hermenéutica y ciencias humanas, libro editado por Alain Verjat en 1989, es decir, hace treinta años. Se trata de la propuesta de un diagnóstico clínico de las configuraciones imaginarias y de una tipología psicoterapéutica. No conocemos otros intentos que dirijan su atención a una consolidación teórica que incluya a las ciencias médicas. La neurología, que creció a pasos agigantados desde la década de los noventa, podría ser de gran ayuda para una actualización teórica. Desde luego, es una empresa complicada por la compartimentación a la que han sido obligadas las ciencias, la especialización extrema que aún divide a las ciencias sociales y las humanidades y a las ciencias médico-biológicas. Sin duda, un esfuerzo de este tipo, inter-, multi- o transdisciplinar, requiere de un equipo con el mismo interés, capaz de reunir los recursos necesarios en proyectos de mediano y largo plazos que arroje resultados que alienten la propagación de otros que contribuyan a una mejor comprensión de las motivaciones de nuestra especie, motivaciones que son representadas artísticamente por nuestros escritores.

Es difícil decidir si este mundo globalizado soporta aún las ideas de nación y raza como para mantener las categorías decimonónicas de "literatura mexicana" o "literatura hispanoamericana". No obstante, la perspectiva de la mitocrítica - si se basa en un análisis arquetípico, si se basa en una constante investigación interdisciplinaria que considere diferentes aspectos de la conducta del hombre- ofrece efectivamente la posibilidad de unos estudios literarios que nos ayuden a comprender mejor a los escritores y las obras actuales y futuros, sean de la región que sean, y sobre todo a comprender mejor a los escritores y las obras pasados que se inscriben en una época que sí puede ser nacional o continental, propia de un pueblo o de una raza en una época y un espacio determinados que son parte de nuestro presente. Esas configuraciones son las que han dado como resultado, junto con el desarrollo tecnológi$\mathrm{co}$, las peculiaridades de lo local (que hay que diferenciar de lo nacional) en el contexto global.

A las reflexiones teóricas generales anteriores debemos sumar las particulares metodológicas del estudio del mito en la literatura mexicana. El mito no sólo debe ser identificado y descrito, ni debe ser únicamente analizado desde la perspectiva de su reescritura, sino que en ocasiones debe ser traducido, como propone la actual escuela inglesa 
del estudio del mito. Esta traducción es particularmente necesaria si se considera la condición global de la cultura. La traducción rebasa los aspectos propios de los estudios de traducción literaria y también, sobre todo, la consideración de los modos de transferencia del mito entre culturas y épocas. Y es precisamente aquí donde resultan más pertinentes estos estudios en la literatura mexicana, que como dijimos es sincrética y diversa. De qué modo son llevados los mitos a una lengua diferente o - quizá más importante- a un nuevo medio. Si la mitología mexicana nace precisamente de la traducción posterior a la conquista, es preciso comenzar a trabajar estas representaciones actualizadas (a veces por frailes a quienes mucho se debe) y sus asimilaciones en los escritores que leyeron esas historias casi siempre en traducción y quienes luego fueron también traductores. No debemos olvidar que estas traducciones conllevan casi siempre implicaciones políticas, religiosas o económicas que no es posible soslayar en una hermenéutica del mito como la que proponía Gadamer, una hermenéutica que tomara en cuenta el diálogo del mito con la ciencia. En época de crisis la resiliencia del mito puede ofrecer sin duda diversas lecciones, puesto que, como señalara el filósofo alemán, "el mito tiene, en relación con la verdad, el valor de ser la voz de un tiempo originario más sabio" (GADAMER, 1997, 169).

\section{REFERÊNCIAS}

ARTE Y FOLKLOR. MÉXICO de Aranza Zu López (2018). Final Quetzalcóatl en Cheonan World Dance Festival 2018. Video de YouTube disponible en: <https://www.youtube.com/watch?v=YFFpa7BFBKo>. Acceso el: 10 sep. 2019.

BARTRA, Agustí. Quetzalcoatl. México: Fondo de Cultura Económica, 1960.

DURAND, Gillbert. Las estructuras antropológicas del imaginario. Introducción a la arquetipología general. México: Fondo de Cultura Económica, 2004.

La imaginación simbólica. Buenos Aires: Amorrortu, 2007.

De la mitocrítica al mitoanálisis. Figuras míticas y aspectos de la obra. Barcelona: Anthropos, 2013.

GADAMER, Hans-Georg. Mito y razón. Barcelona: Paidós, 1997.

HELGUERA, Luis Ignacio. Antología del poema en prosa en México. México: Fondo de Cultura Económica, 1993.

LÓPEZ-PORTILLO Y PACHECO, José. Quetzalcoatl. Barcelona: Salvat Editores, 1976. 
LOSADA GOYA, José Manuel (ed.) (2015). Nuevas formas del mito. Una metodología interdisciplinar. Berlín: Logos Verlag, 2015.

Mitos de hoy. Ensayos de mitocrítica cultural. Berlín: Logos Verlag, 2016.

NOTICIEROS TELEVISA. ¿Qué es el bastón de mando que le darán a AMLO? Televisa.News, 29 de noviembre de 2018. Disponible en: <https://noticieros.televisa.com/historia/que-es-el-baston-de-mando-que-le-daran-a-amlo/>. Acceso el: 10 sep. 2019.

NOTIMEX. Leyenda de Quetzalcóatl conquista a Corea del Sur. El Universal, 21 de septiembre de 2018. Disponible en: <http://www.eluniversal.com.mx/cultura/leyenda-de-quetzalcoatl-conquista-corea-del-sur>. Acceso el: 10 sep. 2019.

RAMÍREZ, Elisa (2002). Historia del sabio señor Quetzalcóatl. Arqueología Mexicana, núm. 53, pp. 50-53.

VERJAT, Alain. El retorno de Hermes. Hermenéutica y ciencias humanas. Barcelona: Anthropos, 1989.

Data do recebimento: 15 setembro 2019

Data da aprovação: 08 novembro 2019 


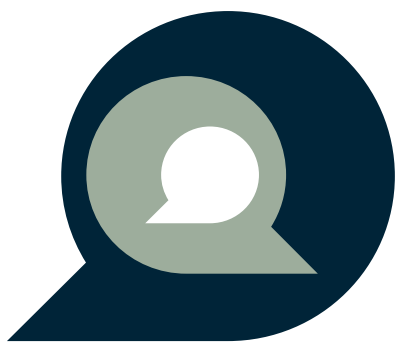

